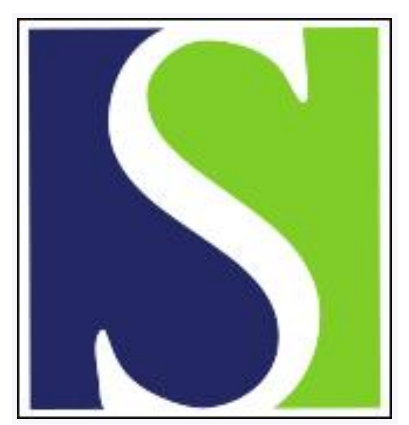

Scand J Work Environ Health 2010;36(3):231-241

https://doi.org/10.5271/sjweh.2878

Published online: 01 Dec 2009, Issue date: 01 May 2010

Historical exposure to mercury among Norwegian dental personnel

by Svendsen K, Syversen T, Melø I, Hilt B

Affiliation: Department of Industrial Economics and Technology Management, Norwegian University of Science and Technology, N-7491 Trondheim, Norway. Kristin.svendsen@iot.ntnu.no

Refers to the following texts of the Journal: 1990;16(4):284-288 1993;19 suppl 1:45-49

The following articles refer to this text: 2010;36(5):430-431;

2011;37(6):539-546; 2012;38(6):546-552

Key terms: amalgam; copper amalgam; dental nurse; dental personnel; dentist; exposure; exposure assessment; historical exposure; mercury; Norway; nurse

This article in PubMed: www.ncbi.nlm.nih.gov/pubmed/19953215 


\title{
Historical exposure to mercury among Norwegian dental personnel
}

\author{
by Kristin Svendsen, PhD, ${ }^{1}$ Tore Syversen, Dr Philos, ${ }^{2}$ Inger Melø, McO, ${ }^{3}$ Bjørn Hilt, MD ${ }^{4,5}$
}

\begin{abstract}
Svendsen K, Syversen T, Melø I, Hilt B. Historical exposure to mercury among Norwegian dental personnel. Scand $J$ Work Environ Health. 2010;36(3):231-241.

Objectives Due to public concern in Scandinavian countries about the health situation of dental nurses, the Norwegian Ministry of Labor and Social Inclusion initiated a project to look at previous exposure to metallic mercury and its possible effects on dental personnel. The aims of this part of the study were to: (i) describe Norwegian dental personnel's exposure to mercury during the last 50 years, (ii) develop a model for scoring that reflects the cumulative exposure on an individual basis, and (iii) relate the calculated score to earlier measured levels of mercury in urine.
\end{abstract}

Methods We obtained lists of previous and current dental employees in both the private and public sector and mailed them a questionnaire concerning their working conditions. We received a response from 655 dental nurses and 452 dentists. We also obtained urine mercury levels measured between 1970-1990 for 143 (22\%) of the dental nurses and $130(29 \%)$ of the dentists.

Results The results revealed a widespread exposure to mercury in both the individual exposure score and the measured mercury values in urine. For most respondents, however, the level of exposure to mercury seemed to be low. The use of copper amalgam, which is heated before it is applied, is of particular concern as a significant source of mercury exposure in dental personnel.

Conclusion It seems evident that the exposure to mercury among dental personnel varies substantially; this is important to take into account when making exposure assessments for this group of workers.

Key terms amalgam; copper amalgam; dental nurse; dentist; exposure assessment; Norway; nurse.

During the last two decades, there has been some concern in Scandinavian countries as to whether dental personnel have suffered long-term deleterious health effects from their previously assumed, low level, occupational exposure to metallic mercury from dental amalgam (1-7). One of the main challenges has been to assess the amount of mercury to which dental personnel have been exposed, preferably on an individual level. Studies of exposure levels in dental clinics have shown mostly low levels of mercury exposure, as indicated both by measured levels in the air at dental clinics and the urine of employees (8-11). Such results have, however, been linked neither to short- nor long-term health effects.

The acute toxic effects of metallic mercury on central nervous system functions are well known. Symptoms of mercury poisoning include tremors, reduced psychomotor speed, paresthesias, and a fairly distinct constellation of psychological symptoms, such as nervousness, shyness, blushing, irritability, and lability of mood. Mild forms of this syndrome are termed micromercurialism, whereas more grave conditions, entailing psychotic symptoms, are called erethism (12).

Some previous studies on the health effects of mercury exposure have included exposure scores for the analyses of possible relationships between exposure to mercury and different outcomes (13), but most have applied biological indicators of exposure - mainly measurements of the current mercury levels in urine $(4-6,14)$.

Owing to the growing public concern over the health situation of dental nurses, the Norwegian Ministry of

1 Department of Industrial Economics and Technology Management, Norwegian University of Science and Technology, Trondheim, Norway.

2 Department of Neuroscience, Norwegian University of Science and Technology, MTFS, Trondheim, Norway.

3 County Public Dental Services, County of Sør Trøndelag, Trondheim, Norway.

4 Department of Occupational Medicine, St Olavs University Hospital, Trondheim, Norway.

5 Department of Public Health and General Practice, Faculty of Medicine, Norwegian University of Science and Technology, Trondheim, Norway.

Correspondence to: Dr K Svendsen, Department of Industrial Economics and Technology Management, Norwegian University of Science and Technology, N-7491 Trondheim, Norway. [E-mail: Kristin.svendsen@iot.ntnu.no]. 
Labor and Social Inclusion initiated a project in order to investigate previous exposure to mercury and its possible late health effects among both dental nurses and dentists. A slightly increased occurrence of cognitive symptoms among Norwegian dental personnel has recently been published (15) based on a questionnaire which comprised the first part of the project. The aims of this part of the study were to: (i) elucidate and describe Norwegian dental nurses' and dentists' exposures to mercury during the last 40-50 years, (ii) develop a model for a relative score that reflects the cumulative exposure to mercury on an individual basis, and (iii) validate the calculated score by relating it to mercury urine values measured earlier.

\section{Mercury in dental amalgam and determinants of exposure}

Dental silver amalgam contains 50\% metallic mercury by weight and a metal alloy composed of silver (about $70 \%$ ), tin (about $25 \%$ ), copper (1-6\%) and zinc (0-2\%). Copper amalgam was a special kind of amalgam that was previously commonly used for the restoration of deciduous teeth in many countries. It consisted of 70\% metallic mercury and $30 \%$ copper. During preparation, solid tablets of this material had to be heated above the melting point of the alloy. Inhalation of metal vapor during this process resulted in a possible source of significant exposures. After the preparation of all the types of amalgam, it was also common that surplus mercury was removed, usually by pressing it through a rag, before the amalgam was used as a filling material.

Throughout the years, different methods for the preparation of dental amalgam have been applied. Initially, amalgam was mixed in a mortar after the manual weighing of each component; later it was prepared in self-made capsules or in semi-automatic amalgamators. Eventually, pre-produced capsules were used. Each of these methods are briefly described below.

In the 1950s and 1960s, the most commonly used method was the preparation of dental amalgam in a mortar, where metallic mercury and metal powder were weighed separately and mixed together manually. We have also been told that the amalgam was often further processed in the palm of the hand to keep it smooth and malleable until it was to be used.

Some clinics also employed self-produced capsules during this period. These were filled with mercury and metal alloy that were mixed and shaken before use. The process entailed a significant risk for spills when the capsules were filled, broke during shaking, or became otherwise leaky during filling and mixing.

Another method, often used in Norwegian dental clinics in the 1970s and 1980s, was the preparation of amalgam in a so-called "Dentomat" or similar semi-automatic mixing devices. In this process, mercury and metal powder were added separately to individual chambers where dosage and mixing took place automatically in a closed system. The mix could be adjusted to be either wet or dry amalgam. There was a risk of spillage during the filling of the Dentomat or when the amalgam was too wet.

During the late 1980s, pre-produced amalgam capsules became available in Norwegian dental healthcare, where proper dosages of mercury and metal powder had been mixed by the manufacturer and were delivered in a closed and solid system. In this method, the quantities of metallic mercury and alloy were so precise that squeezing out excess mercury eventually became unnecessary.

The use of copper amalgam, which was applied in some countries, entailed a source of significant exposure to mercury vapor. Copper amalgam was easier to insert as a filling as it was smooth. It was also considered to have a better antibacterial effect, which reduced the need for excavation of the affected tooth, and it was, therefore, commonly used for the treatment of deciduous teeth. When preparing copper amalgam from a solid form, tablets were heated over a spirit burner until liquefied at temperatures up to $225^{\circ} \mathrm{C}$ (16). The melted metal was then transferred to a mortar, and finally to a textile rag, where excess mercury was squeezed out. In most Norwegian dental clinics, the use of copper amalgam was stopped in the early 1980s, but, according to local registers, some dentists still purchased copper amalgam as late as 1987.

Previous studies have aimed at elucidating which factors could be the main determinants for mercury exposure in dental personnel. There have been, however, substantial differences in conditions, equipment, and routines for dental treatment among countries. Therefore, such factors are not necessarily the same everywhere.

There are only a few reliable fulltime exposure measurements from air samples in dental clinics. From studies conducted before 1970, one study of 50 dental clinics in New York City, USA, showed mean mercury vapor concentrations of $0.02 \mathrm{mg} / \mathrm{m}^{3}$ in the breathing zone of the dentists. Only $2 \%$ of the measurements were $>0.1 \mathrm{mg} / \mathrm{m}^{3}$. When particulate mercury was included, the mean air level was $0.045 \mathrm{mg} / \mathrm{m}^{3}$ and $14 \%$ of the measurements were $>0.1 \mathrm{mg} / \mathrm{m}^{3}$ (17). Another study from the US incorporating 59 clinics reported that exposure in the breathing zone reached as much as $0.18 \mathrm{mg} / \mathrm{m}^{3}$. Approximately $10 \%$ of the dentists had exposure levels $>0.1 \mathrm{mg} / \mathrm{m}^{3}$ while $80 \%$ had exposure levels $<0.01 \mathrm{mg} / \mathrm{m}^{3}$ (18).

The literature refers to the work of Frykholm (19), who performed measurements in Swedish dental clinics before 1970 using direct reading instruments over a period of 25 minutes. He showed that the mercury exposure levels for dentists and dental nurses varied from $<0.01 \mathrm{mg} / \mathrm{m}^{3}$, for normal amalgam work in wellventilated rooms, to $0.4 \mathrm{mg} / \mathrm{m}^{3}$ when copper amalgam was used in small rooms.

In the years between 1970 and 1980, one study 
covering 23 dental clinics in Alberta, Canada, reported concentrations in the breathing zone of $<0.055 \mathrm{mg} / \mathrm{m}^{3}$ in 22 clinics. The median level of mercury vapor in the operating room was found to be $0.023 \mathrm{mg} / \mathrm{m}^{3}$ (20). A Norwegian study of 15 clinics reported a mean level of $0.043 \mathrm{mg} / \mathrm{m}^{3}$; the level was $<0.020 \mathrm{mg} / \mathrm{m}^{3}$ in $50 \%$ of the clinics. In one clinic, the mean exposure level in the operating room was found to be $0.4 \mathrm{mg} / \mathrm{m}^{3}$ (9).

After 1980, there is one report from Sweden where the median level of mercury vapor in 82 clinics was $<0.002 \mathrm{mg} / \mathrm{m}^{3}$ in public service clinics and $<0.0036 \mathrm{mg} / \mathrm{m}^{3}$ in private clinics. The measurements were taken in the breathing zone of the dentists (11).

All the aforementioned studies seem to have used short-time measurements with direct reading instruments for mercury vapor detection. Measurement times were mentioned in only two of the five studies.

One Swedish study from the 1990s did, however, report time-weighted average air mercury levels during normal 8-hour working days. Measurements were performed by use of "hydrar tubes" and showed a median air level of mercury of $1.8 \mu \mathrm{g} / \mathrm{m}^{3}$ for the dentists and $2.1 \mu \mathrm{g} / \mathrm{m}^{3}$ for the dental nurses (21).

The most recent study measuring mercury in dental clinics is from 2004 in Great Britain. It reported results from 153 dosimeters worn by dentists. The mean concentration was $0.029 \mathrm{mg} / \mathrm{m}^{3} ; 29 \%$ of the measurements were $>0.025 \mathrm{mg} / \mathrm{m}^{3}$ (22).

However, most available studies that have looked at determinants for exposure to metallic mercury in dental clinics have used mercury levels in urine as an indicator of exposure.

For this purpose, a complete 24-hour urine sample is preferable, but in practice it is difficult to obtain. As a surrogate for timed samples, spot samples of the first morning urine, corrected for creatinine or specific gravidity, are recommended. After short-term exposure, the maximum mercury level in urine is not reached until several weeks after exposure, and the half time of mercury is 40-60 days when a one compartment model is assumed (23). The time of the day when the urine is collected is a significant factor for both the level of mercury in urine and the creatinine-corrected values (24). In Norway, the reference value from objects with no occupational exposure to metallic mercury has been $100 \mathrm{nmol} / \mathrm{l}$ (8); while the new biological limit value in Norway today is $30 \mu \mathrm{g}$ mercury/g creatinine, which corresponds to $150-200 \mathrm{nmol} / \mathrm{l}$. The mean background concentration of urinary mercury has, however, been reported to be $20 \mathrm{nmol} / \mathrm{l}$ with a $95^{\text {th }}$ percentile of $100 \mathrm{nmol} / \mathrm{l}(8)$.

Important factors that may influence exposure and, thus, also the levels of mercury in urine include: (i) the use of a textile rag to squeeze out excess mercury, (ii) the number of years a clinic has used the same premises, (iii) the number of amalgam treatments per week, (iv) whether a mercury spill has occurred in the clinic, and (v) whether Dentomat or capsules were used $(4,5,10,11,13,25)$.

Some studies have also reported that the number of amalgam surfaces that were removed or polished has had an effect on measured mercury in urine (10) and that the removal of amalgam fillings can give dental personnel an equally high mercury exposure as when new fillings are put in place (26). Others have, however, not shown any relationship between the number of removed fillings and urinary mercury levels among the dental staff $(4,25)$.

\section{Method}

This study was conducted as a questionnaire survey during the spring of 2006 among individuals who had worked in the dental health services in three counties forming the central part of Norway. We obtained lists of previous and current employees from both private and public service dentists. In this way, we identified 2247 dental personnel, born between 1913 and 1985, who were asked to participate in the study by responding to a comprehensive questionnaire on both exposure and health.

In order to learn about previous methods for preparing amalgam and design a suitable questionnaire, we interviewed both dentists and dental nurses who had worked in dental healthcare as early as the 1950s and 1960s. These individuals also demonstrated to us how the work was done in earlier days. Combining this acquired knowledge with previous knowledge about exposure and the factors that influence it, we developed a detailed questionnaire on working conditions at the dental clinics throughout the professional life of the respondents. The questionnaire was tested in a small group of dental personnel before the main study was performed.

In the questionnaire, the participants were asked about their vocational title, at which clinics they had worked, and during what time periods. The participants were also asked if they had ever worked with copper amalgam and, if yes, when they started and stopped using it and how many patients they treated each week using the substance. Similar questions were asked with respect to the various treatment methods (ie, the preparation of amalgam in a mortar, the production of self-produced capsules, and the use of a Dentomat or pre-produced capsules). When the participants had used a Dentomat or similar mixing device, they were also asked how often it was filled, if there had been frequent spills of mercury, whether the amalgam was soft or firm, and whether they had been the ones who filled the Dentomat with mercury and alloy. The questionnaire also inquired about spills of mercury in general, and about flooring, ventilation, and other characteristics of their workplace. 
All questionnaires were read optically using the Teleform software, and the registered data were subsequently checked for scanning and logical errors.

\section{Model for exposure assessment}

Using the questionnaire data, we calculated a total relative exposure score for each participant. A sub-score was constructed for each relevant treatment method that entailed the use of mercury and other features that could influence exposure. The sub-scores included the weekly number of patients treated with the particular method, the number of years the method was used, and an adjustment factor that reflected our assumptions concerning the relative degree of exposure in connection with that particular treatment method. These adjustment factors were based on crude estimates of relative exposure levels - when taking temperature, surface area and frequency of contact with mercury into consideration - and levels reported in the literature. In addition, we developed a clinic sub-score based on: (i) how long there had been a dental clinic on the premises, (ii) what the floor covering had been on the premises, and (iii) if there had been any serious spills of mercury in the clinic. All these sub-scores were then summed up to a relative exposure score for the cumulative exposure to mercury vapor throughout the individual's career in dental healthcare.

The individual total relative scores were calculated by the following formula as the sum of the five different sub-scores for treatment methods and the clinic scores as described in table 1:

$$
5
$$

Relative exposure score $=\Sigma\left(\mathrm{N}_{\mathrm{i}} \times \mathrm{Y}_{\mathrm{i}} \times \mathrm{A}_{\mathrm{i}}\right)+$ clinic score

$$
\mathrm{i}=1
$$

$\left(\mathrm{N}_{\mathrm{i}}=\right.$ number of patients per week for sub-score $\mathrm{i}, \mathrm{Y}_{\mathrm{i}}=$ number of years for sub-score $i, A_{i}=$ adjustment factor for sub-score i). In addition, the sub-scores $1-5$ were adjusted by a factor of 0.5 for each of the years where local air extraction was used.

This relative exposure score is cumulative. To obtain a so-called "intensity score" more suitable for comparison with urine levels of mercury, the relative exposure score was divided by the number of years with exposure to dental amalgam.

For some of the treatment methods, a substantial number of respondents were missing details on the number of patients treated each week. In such cases, and if the number of years for that particular treatment method was given, we replaced the missing number of patients with the median number for the whole study group.

\section{Mercury in urine}

During the period 1955-2000, the Norwegian National Institute of Occupational Health (STAMI in Norwegian) conducted voluntary monitoring of mercury levels in urine for dental personnel in Norway. During this time,

\begin{tabular}{|c|c|c|c|}
\hline Score & $\begin{array}{l}\text { Treatment } \\
\text { method }\end{array}$ & $\begin{array}{l}\text { Adjustment } \\
\text { factor }\end{array}$ & Comments \\
\hline \multicolumn{4}{|l|}{ Sub-score (i) } \\
\hline 1 & $\begin{array}{l}\text { Use of copper } \\
\text { amalgam }\end{array}$ & 10 & $\begin{array}{l}\text { A study conducted in Norwegian dental clinics in } 1974 \text { showed levels of mercury ranging from }<0.01-0.4 \\
\mathrm{mg} / \mathrm{m}^{3} \text {. The measurements were done with a Mercury Vapor Sniffer and in standardized locations in the } \\
\text { clinics. All measurements }>0.05 \mathrm{mg} / \mathrm{m}^{3} \text { were found in clinics using copper amalgam(9) }\end{array}$ \\
\hline 2 & $\begin{array}{l}\text { Mixing } \\
\text { amalgam in a } \\
\text { mortar }\end{array}$ & 0.4 & $\begin{array}{l}\text { Metallic mercury and metal powder were weighed separately and mixed together manually. This will give an } \\
\text { enhanced surface area of mercury. }\end{array}$ \\
\hline 3 & $\begin{array}{l}\text { Production } \\
\text { of self-made } \\
\text { capsules }\end{array}$ & 0.3 & $\begin{array}{l}\text { The process entailed a significant risk for spills both when the capsules were filled, when they broke during } \\
\text { shaking, or in other ways became leaky during filling and mixing }\end{array}$ \\
\hline 4 & $\begin{array}{l}\text { Use of an } \\
\text { amalgamator } \\
\text { (dentomat) }\end{array}$ & $\begin{array}{l}0.2,0.3 \\
\text { or } 0.4\end{array}$ & $\begin{array}{l}\text { Factor } 0.2 \text { was given as base value for the use of a dentomat, factor } 0.3 \text { was given if the respondent re- } \\
\text { ported that the amalgam was wet or if the dentomat was filled } \geq 1 \text { week or if there was a spill } \geq 1 \text { month } \\
\text { when filling the dentomat or if it was most often the respondent who filled the dentomat. If all } 4 \text { factors } \\
\text { were fulfilled, the factor } 0.4 \text { was given. A Swedish investigation has shown high levels of mercury vapor } \\
\text { in the front of the amalgamators. Visible droplets of mercury are seen in some cases. The level of mercury } \\
\text { as mean of } 1-3 \text { minutes registration in the breathing zone at the amalgam preparation area varied between } \\
<1.0-18.7 \mu \mathrm{g} / \mathrm{m}^{3}(11)\end{array}$ \\
\hline 5 & $\begin{array}{l}\text { Use of pre- } \\
\text { produced } \\
\text { capsules }\end{array}$ & 0.1 & $\begin{array}{l}\text { Delivered in a closed and solid system. By this method, the quantities of metallic mercury and alloy were so } \\
\text { precise that squeezing out excess mercury eventually became unnecessary. Exposure was supposed to be } \\
\text { low but was not totally eliminated }\end{array}$ \\
\hline Clinic score & & $\begin{array}{l}1,5,8, \text { or } \\
10\end{array}$ & $\begin{array}{l}\text { If there had been poor routines for the handling of mercury leftovers and spills in the clinic, the adjustment } \\
\text { factor was set to } 5 \text {, if there was a floor covering of wooden panels or carpets, the adjustment factor was } 8 \\
\text { and if there have been poor routines for handling mercury leftovers, major spills and there was floor cover- } \\
\text { ing of wooden panels or carpets, the adjustment factor was } 10 \text {. A Norwegian study has shown that it is pos- } \\
\text { sible to keep the exposure level }<0.01 \mathrm{mg} / \mathrm{m}^{3} \text {, but that some clinics without any obvious reason had levels } \\
\text { in the range } 0.1 \mathrm{mg} / \mathrm{m}^{3}(9)\end{array}$ \\
\hline
\end{tabular}

Table 1. Adjustment factors for the different sub-scores for the treatment method and clinic sub-score. 
STAMI analyzed a total of 4030 samples from 2028 individuals. The results showed a decrease of about $90 \%$ in urine mercury levels from the 1960s to the 1990s. The concentration among dentists showed a median of $240 \mathrm{nmol} / \mathrm{l}$ (range 83-528) in the 1960s and $22 \mathrm{nmol} / \mathrm{l}$ (range 6-76) in the 1990s. The corresponding figures for dental nurses were $160 \mathrm{nmol} / \mathrm{l}$ (range 7.5-3100) and $21 \mathrm{nmol} / \mathrm{l}$ (range 5-133). The urine samples were analyzed using flameless atomic absorption (8).

In the questionnaires, we requested written permission from each participant to access results from any previously collected urine tests available at STAMI. Of the 273 respondents with available urine values, most respondents had one sample, but there were up to ten samples for one person. The urine values were not creatinine corrected. These urinary values were later collated to two variables: one for the average urinary value for each person and the other for the highest observed value for each person. The urine data were used as a crude measure of former exposure and compared to the individually calculated relative exposure scores. The urine values were given as urine mean, (ie, the mean urine value of all samples from the same person) and urine maximum (ie, the highest value measured for each individual).

\section{Statistical analysis}

We used the SPSS version 14.0 to analyze data (SPSS Inc, Chicago, IL, USA). Most analyses were performed with descriptive statistics, and univariate analysis of variance. We performed correlations between the urinary mercury values and the calculated exposure score using a non-parametric method (Spearman's rho).

\section{Ethical considerations}

The ethical committee for medical research in Central Norway approved the study; the Norwegian Social Science Data Services provided a license for personal registrations.

\section{Results}

Out of the 1224 dental nurses who were invited to participate, 690 (56.4\%) responded and 655 confirmed having worked as a dental nurses. The response rate for the dentists was 452 out of 922 (49\%). The mean age of the participating dental nurses and dentists was 53.3 [standard deviation $(\mathrm{SD})=11.0)$ ] and $54.3(\mathrm{SD}=13.8)$ years, respectively. Figure 1 shows the distribution of the years of first employment in dental care for the participating dental nurses and dentists. The mean duration of their employment in dental care was $21.9(\mathrm{SD}=13.3)$ and $24.0(\mathrm{SD}=13.4)$ years, respectively. For the dental nurses, a mean of 18.1 ( $\mathrm{SD}=9.3$ ) of the employed years had been before 1990. For dentists, the corresponding figure was $18.7(\mathrm{SD}=8.6)$ years.

Table 2 shows the main factors assumed to have influenced exposure to mercury as reported by the dental nurses and dentists themselves (eg, use of copper amalgam, mixing amalgam in a mortar, production of capsules, use of the Dentomat, mercury spills, or frequent handling of amalgam in the hands). The dental nurses reported more of all of these features than the dentists, in particular with respect to spills and the handling of amalgam in the palm.

Of the dental nurses, 201 reported having used copper amalgam for a mean of 8.3 (SD 7.6) years while 108 dentists reported using it for an average of 6.6 (SD 5.4) years. At the most, the two groups reported having had 16.7 (SD 19.2) and 7.7 (SD 9.3) patients a week who were treated with the use of copper amalgam. Only $0.5 \%$ of the dental nurses and $0.9 \%$ of the dentists reported having used any kind of ventilated hoods when heating copper amalgam.

The use of ordinary amalgam - either prepared in a mortar, by the Dentomat, or in capsules - was stable from the 1960s onwards. Typically, 40-50 patients a week were treated with amalgam while, from the 1990 s, the use of ordinary amalgam decreased to $25-30$

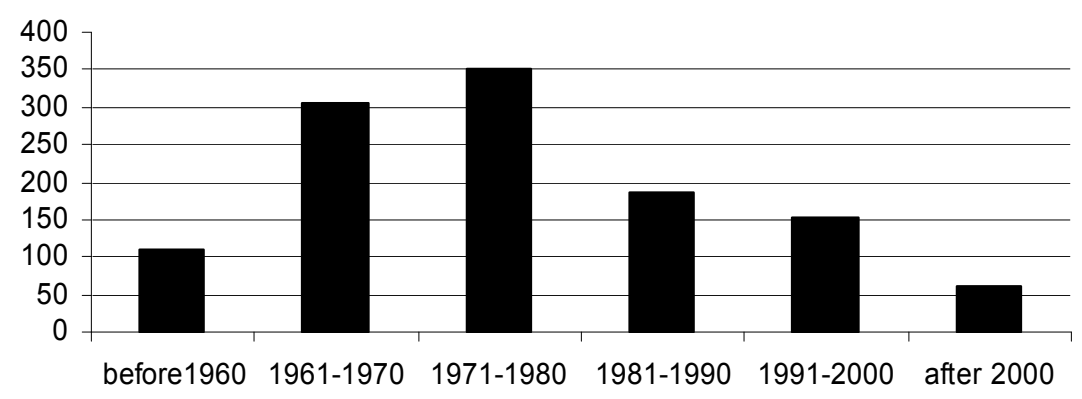

Number of respondents with first employment in dental care
Figure 1. The distribution of the years of first employment in dental care for the 1079 respondents. 
Table 2. Factors assumed to have influenced exposure to mercury among dental personnel, and the proportion of the 655 dental nurses and the 452 dentists who reported having used the different working methods. All numbers are given as the percentage of positive answers in each occupational group.

\begin{tabular}{lcc}
\hline Variable & $\begin{array}{c}\text { Dental nurses } \\
(\%)\end{array}$ & $\begin{array}{c}\text { Dentists } \\
(\%)\end{array}$ \\
\hline Used copper amalgam & 41.6 & 30.7 \\
Used a mortar & 42.6 & 34.1 \\
Produced own capsules & 13.8 & 9.6 \\
Often used the Dentomat & 82.1 & 54.2 \\
$\quad$ Wet amalgam & 54.9 & 22.6 \\
$\quad$ Filled the Dentomat $>$ 1/week & 12.9 & 8.8 \\
Often filled the Dentomat on your own & 79.4 & 9.0 \\
$\quad$ Experienced a spill each time the & 32.8 & 7.0 \\
$\quad$ Dentomat was filled & & \\
There was a great spill of mercury & 7.7 & 3.6 \\
in the room at least once & 67.4 & 9.1 \\
Often handled the amalgam in the palm & & \\
\hline
\end{tabular}

treatments a week. Figure 2 shows a decrease in the reported use of copper amalgam from $69.5 \%$, for those who had started as a dental nurse before 1970 , to $5.7 \%$ for those who had started after 1990. The use of a mortar shows the same strong decrease, while the Dentomat was used most frequently by those who started to work between 1970-1980. Figure 3 shows the same trends for the dentists' use of the different methods. The dental nurses and dentists, who started to work before 1970, reported the same degree of work with a mortar; for all other methods and start-up years, the dental nurses reported greater use of all treatment methods.

Table 3 gives the $95^{\text {th }}$ and $75^{\text {th }}$ percentiles for the year reported for the termination of the use of the four treatment methods that are assumed to have contributed to the highest exposure to mercury. This means that, by $1991,95 \%$ of both dental nurses and dentists had terminated the use of copper amalgam.

When we entered the relevant elements from the above information into the formula for the cumulative exposure assessment, the scores showed a wide distribution for both dental nurses and dentists, with a clear tendency for higher scores in the former. Table 4 shows core statistics on the calculated relative exposure scores for both groups. Even if we substituted the missing number of patients each week with the group median, only 713 (64\%) of the respondents answered the most important questions necessary for a valid, relative exposure score (ie, those regarding the years of commencement and termination of the use of copper amalgam and the Dentomat).

Figure 4 shows the development of the relative exposure scores with their SD for both groups, dependent on the year when they started their employment in dental care. We gained access to the results from previous measurements of mercury in urine for $143(22 \%)$ of the participating dental nurses and $130(29 \%)$ of the dentists. Figure 5 shows the distribution of the years when the urine values were analyzed. Table 5 shows available urinary mercury values for the respondents. More than one urine measurement was available in the registry for $37 \%$ of the dental personnel. When looking at the whole data set, we found a weak positive correlation between the urinary mercury values and both the relative exposure and intensity scores. For the relative exposure score, Spearman's Rho was $0.24(\mathrm{P}=0.001)$ and $0.19(\mathrm{P}=0.008)$ for the maximum and average urine

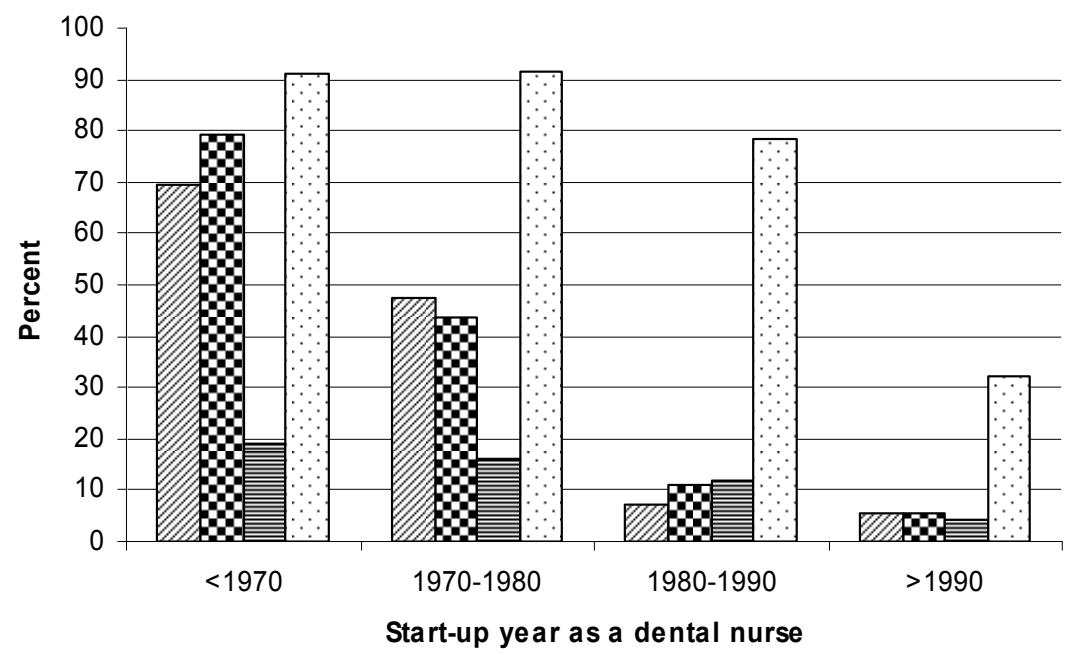

\begin{tabular}{|ll|}
\hline$\square$ Use of copper amalgam & $\square$ Use of a mortar \\
目 Use of self- made capsules & $\square$ Frequent use of a Dentomat \\
\hline
\end{tabular}

Figure 2. Percent of the 655 dental nurses who reported using the different methods in relation to start-up year as a dental nurse 


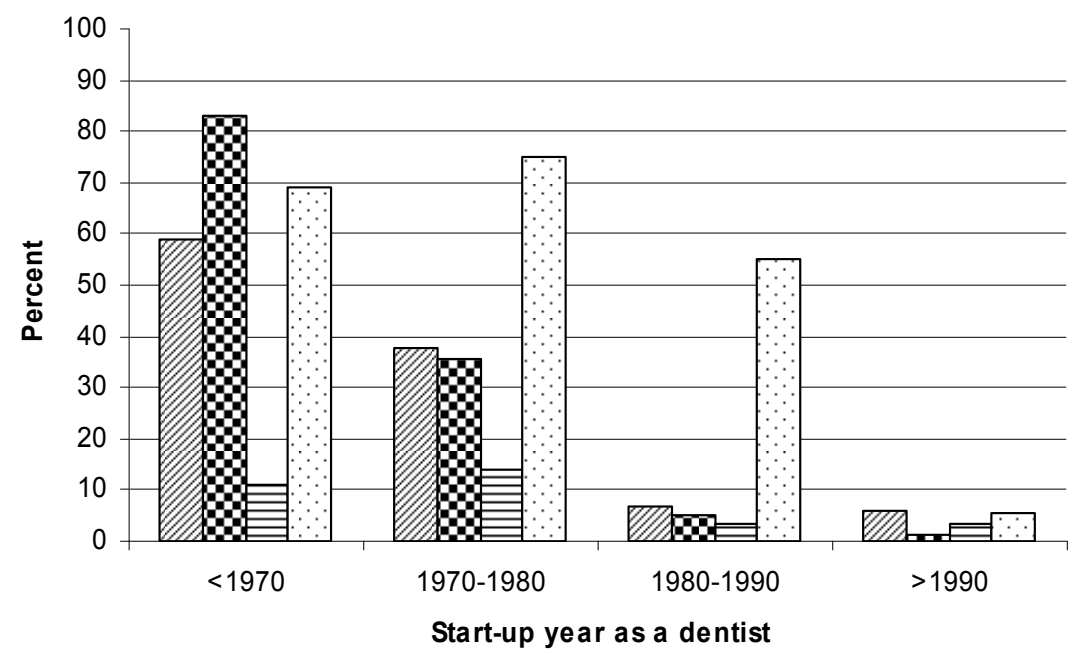

\begin{tabular}{|ll|}
\hline$\square$ Use of copper amalgam & $\square$ Use of a mortar \\
目 Use of self- made capsules & $\square$ Frequent use of a Dentomat \\
\hline
\end{tabular}

Figure 3. Percent of the 452 dentists who reported using the different methods in relation to start-up year as a dentist.

Table 3. The $95^{\text {th }}$ and $75^{\text {th }}$ percentiles for the years reported for the termination of the four treatment methods that are assumed to give the highest exposure to mercury. The results are given for the dental nurses and the dentists.

\begin{tabular}{|c|c|c|c|c|c|c|}
\hline \multirow[t]{2}{*}{ Variable } & \multicolumn{3}{|c|}{ Dental nurses } & \multicolumn{3}{|c|}{ Dentists } \\
\hline & $\begin{array}{l}\text { Number of } \\
\text { respondents }\end{array}$ & $\begin{array}{c}95^{\text {th }} \\
\text { percentile }\end{array}$ & $\begin{array}{c}75^{\text {th }} \\
\text { percentile }\end{array}$ & $\begin{array}{l}\text { Number of } \\
\text { respondents }\end{array}$ & $\begin{array}{c}95^{\text {th }} \\
\text { percentile }\end{array}$ & $\begin{array}{c}75^{\text {th }} \\
\text { percentile }\end{array}$ \\
\hline In what year did you terminate the use of a mortar? & 216 & 1996 & 1981 & 153 & 1990 & 1980 \\
\hline In what year did you terminate the use of copper amalgam? & 226 & 1991 & 1984 & 146 & 1991 & 1982 \\
\hline In what year did you terminate the use of self-made capsules? & 58 & 2006 & 1995 & 36 & 2005 & 1992 \\
\hline In what year did you start using the Dentomat? & 486 & 1993 & 1983 & 289 & 1995 & 1981 \\
\hline In what year did you terminate the use of the Dentomat? & 458 & 2005 & 1999 & 280 & 2005 & 1999 \\
\hline
\end{tabular}

levels, respectively. For the intensity score, the corresponding Spearman's Rho were $0.27(\mathrm{P}=0.000)$ and $0.20(\mathrm{P}=0.004)$. Table 6 shows the correlation between the relative exposure score in four groups for the participants with a valid score and the available urinary mercury values. The group mean urinary level increases as the grouped relative exposure score increases, although not in a statistically significant manner.

\section{Discussion}

The results of this study are in concordance with earlier studies that have shown that dental nurses have been more severely exposed to mercury than dentists (10). Both the answers to our questionnaire and the previous measurements of mercury in the urine samples from our participants reveal higher exposures among dental nurses. But, the results also show a wide distribution, both in the calculated individual relative exposure scores and the previously measured mercury values in urine. Though most of our respondents seem to have had rather low exposures to mercury, the data showed that some of the respondents probably had been more extensively exposed. Even for dental personnel who were first

Table 4. Core statistics for the calculated relative exposure score for the dentists and the dental nurses who had a valid answer on all important determinants (year of starting and terminating the use of copper amalgam and a Dentomat or had never used these methods). [SD=standard deviation.]

\begin{tabular}{lrrrrrrrr}
\hline & $N$ & Mean & SD & Median & $\begin{array}{c}\text { Mini- } \\
\text { mum }\end{array}$ & \multicolumn{2}{c}{$\begin{array}{c}\text { Maxi- } \\
\text { mum }\end{array}$} & $\begin{array}{c}\text { Geometric } \\
\text { mean }\end{array}$ \\
\hline $\begin{array}{l}\text { Dental nurses } \\
\text { Dentists }\end{array}$ & 440 & 829 & 1371 & 381 & 9 & 12120 & 374 \\
\hline Total & 712 & 561 & 926 & 270 & 9.3 & 7170 & 255 \\
\hline
\end{tabular}




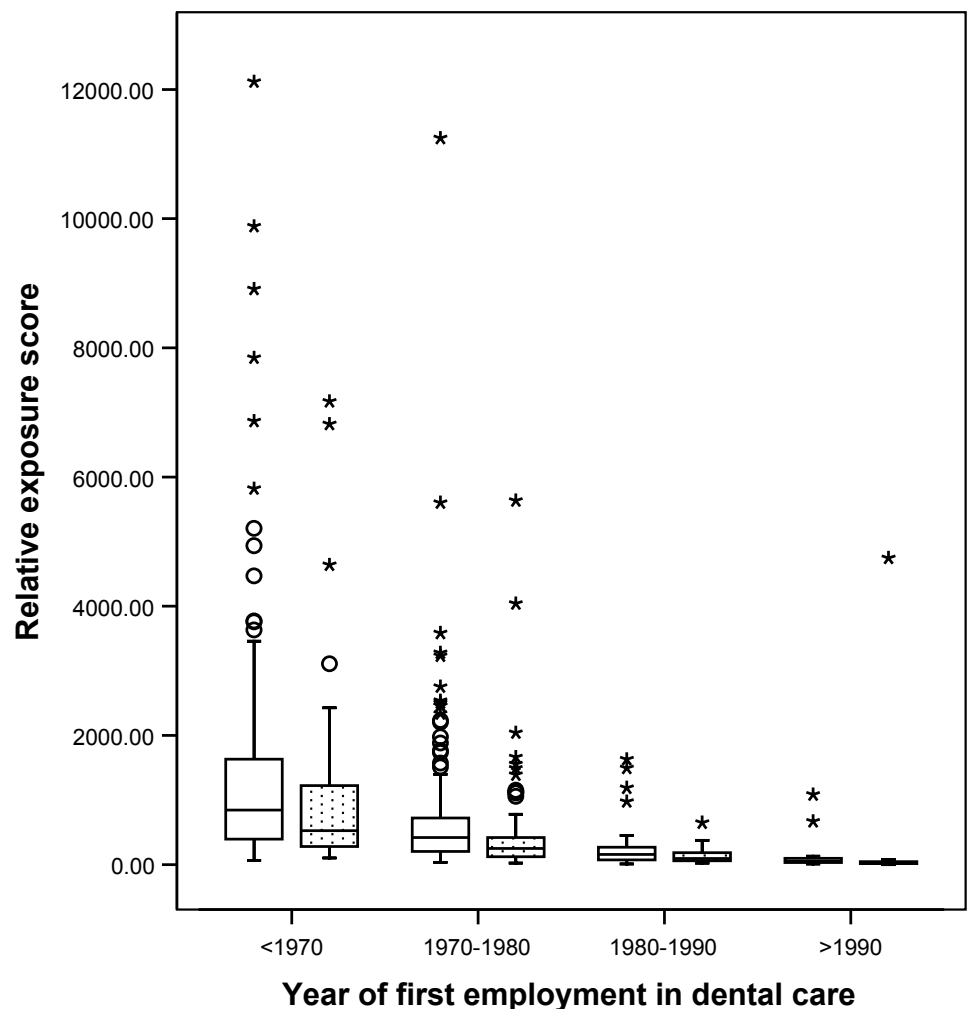

$\square$ Dental nurses

Dentists

Figure 4. Box plots of the relative exposure scores for the dental nurses and the dentists dependent on the year they started their employment in dental care. The box plot summarizes the median, quartiles, and extreme values. White boxes to the left are dental nurses, dotted boxes to the right are dentists. Circles are outliers with values between 1.5-3 box lengths from upper or lower edge of the box. The box length is the interquartile range. Crosses are extreme cases with values $>3$ box lengths from the upper edge of the box.

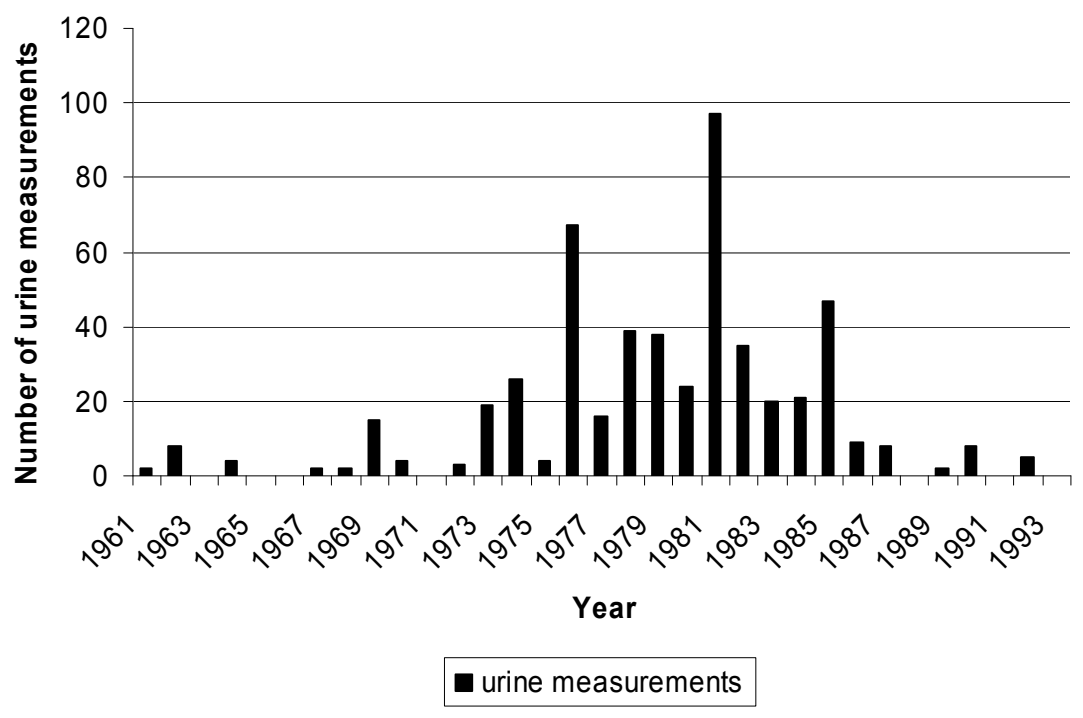

Figure 5. Distribution of the year when the urine mercury measurements were taken for the study group.

Table 5. Median, maximum value, $25^{\text {th }}$ and $75^{\text {th }}$ percentiles, and number of respondents or respondents with urine samples ( $N$ ) for the calculated exposure score for the two groups, the urine values for the groups, and the highest single urine value measured in each group. Both parameters are statistically significantly different between the dental nurses and the dentists with $\mathrm{P}<0.005$.

\begin{tabular}{|c|c|c|c|c|c|c|c|c|}
\hline & \multicolumn{4}{|c|}{ Dental nurses $(\mathrm{N}=143)$} & \multicolumn{4}{|c|}{ Dentists $(N=130)$} \\
\hline & Median & $\begin{array}{l}\text { Maximum } \\
\text { value }\end{array}$ & $\begin{array}{c}25^{\text {th }} \\
\text { percentile }\end{array}$ & $\begin{array}{c}75^{\text {th }} \\
\text { percentile }\end{array}$ & Median & $\begin{array}{c}\text { Maximum } \\
\text { value }\end{array}$ & $\begin{array}{c}25^{\text {th }} \\
\text { percentile }\end{array}$ & $\begin{array}{c}75^{\text {th }} \\
\text { percentile }\end{array}$ \\
\hline Urine mean $(\mathrm{nmol} / \mathrm{l})$ & 49 & 298 & 30 & 85 & 42 & 258 & 30 & 61 \\
\hline Urine maximum (nmol/l) & 59 & 1065 & 31 & 100 & 51 & 305 & 30 & 75 \\
\hline
\end{tabular}


Table 6. Results from the univariate analysis with maximum urine value as dependent variable and relative exposure score in four groups as grouping variable. [SD=standard deviation.]

\begin{tabular}{lccc}
\hline Relative exposure score & $\mathrm{N}^{\mathrm{a}}$ & Mean urine $\max (\mathrm{nmol} / \mathrm{l})$ & $\mathrm{SD}$ \\
\hline Low $(\mathrm{N}=176)$ & 21 & 53 & 29.5 \\
Medium $(\mathrm{N}=176)$ & 39 & 61 & 64.6 \\
High $(\mathrm{N}=177)$ & 51 & 69 & 61.1 \\
Very high $(\mathrm{N}=184)$ & 82 & 90 & 122.0 \\
\hline Total & 193 & 74 & 91.4 \\
\hline
\end{tabular}

a Number of available urine mercury values in each exposure group.

employed in the same decade, the exposure varied substantially. The median levels of mercury in urine, both for dental nurses and dentists, were below the reference value regarding occupational exposure to mercury. The $75^{\text {th }}$ percentile for the maximum urine value for the dental nurses was, however, $100 \mathrm{nmol} / \mathrm{l}$.

The exposure was at its highest for those who started to work in the 1960s and 1970s and decreased gradually thereafter. However, the use of treatment methods that are supposed to result in high exposure to mercury remained frequent in certain clinics up to 1980. It might, therefore, be that some individuals were still substantially exposed to mercury despite the decrease in overall mean exposure. The highest exposures were clearly connected to the heating of copper amalgam. Mercury levels as high as $3 \mathrm{mg} / \mathrm{m}^{3}\left(3000 \mu \mathrm{g} / \mathrm{m}^{3}\right)$ have been reported when using copper amalgam (27). The risk of adverse health effects resulting from such exposures should not be disregarded. The use of copper amalgam started as early as the 1800 s and continued far into the second half of the last century. While one source claimed that the use of copper amalgam was terminated in the 1950s (16), the use of heated copper amalgam has been described in Sweden up to 1987 (28), in New Zealand until 1975 (27) and in Germany up to 1940 and maybe as late as the 1980s (29).

Though copper amalgam can be regarded as the strongest source of exposure to metallic mercury, another substantial source could be spills on the floor, deposited under the furnishings and in slits in the floor covering (9). The handling of mercury in the palm of the hand may also have entailed a risk of metallic mercury vapor exposure, as such handling increases the temperature of the amalgam to above room temperature, leading to higher vaporization. When measuring mercury vapor on the skin right after handling copper amalgam in the bare palm and following hand washing, levels up to $0.2 \mathrm{mg} / \mathrm{m}^{3}$ have been measured (9). Handling amalgam in the palm of the hand was, however, not a factor that was regarded as a significant source of exposure when we started the study and was, therefore, not incorpo- rated in the exposure score when, on second thoughts, it should have been.

From our data, we see that the dental nurses reported having had twice as many patients each week who were treated with the use of copper amalgam compared to the dentists. In regard to the other treatment methods, the dental nurses and the dentists reported the same number of patients each week. This discrepancy is not easy to understand. As there were more dental nurses than dentists who answered, there may be a selection of dental nurses in our study with an extensive use of copper amalgam. The share of the dental nurses who reported having used copper amalgam (42\%) was also higher than that of the dentists $(31 \%)$. This is in agreement with a recently published study where $42 \%$ of dental nurses in public service clinics, and $30 \%$ in private clinics reported that they had used copper amalgam (30).

Our respondents' answers as to what year they stopped using the different treatment methods was somewhat confusing. Some of both the dentists and dental nurses reported using copper amalgam as late as 2000 and thereafter. This is probably due to a misunderstanding as a high copper alloy amalgam has been in use in recent times and differs from the copper amalgam that had to be heated over a flame. The same phenomenon was seen for the use of the mortar. We supposed the use of this method was terminated in the early 1980s, but some dentists and dental nurses reported the use of mortars as late as 2000 . These results may indicate that the wording of the questionnaire was not optimal inspite of our efforts to perfect the questions. Another more worrisome interpretation could be that some dental clinics still use the old fashioned methods for some purposes.

Our calculated exposure score is a relative figure that does not give the exact exposure level, but is aimed at expressing the cumulative exposure during work as a dentist or dental nurse. The model includes numerous factors that were assumed to be of relevance for exposure. The adjustment factors which were used to assess relative exposure intensity were roughly based on available results, measurements and empirical knowledge. The levels measured in Swedish public dental clinics in the early 1980s (11) and the mean levels from Norwegian clinics in the 1970s (9) showed that there was reason to apply a factor of 100 between clinics with good versus bad hygienic practice (including the use of copper amalgam). The values given for the adjustment factors might seem arbitrary, but a typical rise in mercury concentration $\left(0.01-0.1 \mathrm{mg} / \mathrm{m}^{3}\right)$ was found in Norwegian clinics in the 1970s when heating copper amalgam; all clinics with measured levels $>0.05$ $\mathrm{mg} / \mathrm{m}^{3}$ in standardized locations used copper amalgam. The highest level measured was $0.4 \mathrm{mg} / \mathrm{m}^{3}$ and, at the same time, $16 \%$ of the clinics had levels $<0.01 \mathrm{mg} / \mathrm{m}^{3}$ (9). In the Swedish study, the concentration level varied 
between $<0.001-0.024 \mathrm{mg} / \mathrm{m}^{3}$, and no copper amalgam was used in the clinics under scrutiny (11). Thus one can say that exposure based on location, work practice, ventilation, and other working conditions has varied considerably.

One of the weak points in our approach was that we based our calculations on the responses regarding the years of commencement and termination of the different treatment methods and the number of patients treated each week. As was seen from the answers about the year of termination of the different treatment methods, the results were hampered not only by possible misunderstandings, but also from missing information, resulting in a low response rate for the relative exposure score. It has been shown that missing information on exposure, and not erroneous reporting, is the most important cause of misclassification of the determinant in occupational epidemiological studies (31).

Another potential problem was that, before we started our study, the Norwegian media had focused attention on dental nurses' possible health problems stemming from mercury exposure. As a result, some recall bias overstating the exposure among the dental nurses cannot be ruled out. As many of the dentists were the employers of these dental nurses, a "recall" bias in the opposite direction may have occurred among them.

The group mean urine maximum level increased as the relative exposure score increased, although not in a statistically significant manner. The urine value and the score were two different features. The exposure score was a measure of cumulative exposure that entailed both intensity and duration; while the measured urine mercury value was just a spot value at one point in time and, thus, not a measure on cumulative exposure. In addition, the urine samples were collected on a voluntary basis, and although there was some guidance on the collection of the samples (they were asked to take the sample in the morning), there is no guarantee that the samples were taken in a standardized way. In addition, the urine values were not corrected for creatinine or specific gravity and thus not a good measure of exposure. The measured level of urinary mercury only reflects the exposure level for a relatively short period of the working life. Still, this is the only objective measure on exposure that exists, and we think that a measured urine level may give an indication on the working conditions in the clinic at the time of the measurement. Therefore, we find it interesting that we found a positive correlation between the urinary mercury values and both the relative exposure and intensity scores. The correlation for the intensity score was, as expected, slightly better than that of the relative exposure score, which is a cumulative score.

The model to calculate the exposure score was based on Norwegian habits and constructed on the basis of how dental work was performed in Norway. It may, however, be used in other countries as well but should be adjusted to local dental treatment practices.

When assigning individual exposure measures to dental nurses and dentists, it is important to take into consideration all the different conditions of their work in order to identify individual differences in the exposure to mercury. Detailed job-specific questionnaires are supposed to be able to differentiate between high- and low-exposed workers (32), and we believe that our relative exposure score, based on a detailed questionnaire, reflects the cumulative exposure to mercury. From both empirical knowledge, and our calculated relative exposure score, it seems evident that the exposure to mercury among dental personnel varies substantially even within the year intervals for first employment in dental care, which is important to take into account when making exposure assessments for this group of workers.

\section{References}

1. Shapiro IM, Cornblath DR, Sumner AJ, Uzzell B, Spitz LK, Ship II, Bloch P. Neurophysiological and neuropsychological function in mercury-exposed dentists. Lancet. 1982;1:1147-50.

2. Ngim CH, Foo SC, Boey KW, Jeyaratnam J. Chronic neurobehavioural effects of elemental mercury in dentists. $\mathrm{Br}$ J Ind Med. 1992;49:782-90.

3. Ritchie KA, Macdonald EB, Hammersley R, O'Neil JM, McGowan DA, Dale IM, et al. A pilot study of the effect of low level exposure to mercury on the health of dental surgeons. Occup Environ Med. 1995;52:813-7.

4. Echeverria D, Heyer NJ, Martin MD, Naleway CA, Woods JS, Bittner AC. Behavioral effects of low-level exposure to $\mathrm{Hg} 0$ among dentists. Neurotoxicol Teratol. 1995;17:161-8.

5. Echeverria D, Aposhian HV, Woods JS, Heyer NJ, Aposhian MM, Bittner AC jr, et al. Neurobehavioral effects from exposure to dental amalgam $\mathrm{Hg}(\mathrm{o})$ : new distinctions between recent exposure and Hg body burden. FASEB J. 1998;12:971-80.

6. Echeverria D, Woods JS, Heyer NJ, Rohlman DS, Farin FM, Bittner AC jr, et al. Chronic low-level mercury exposure, BDNF polymorphism, and association with cognitive and motor function. Neurotoxicol Teratol. 2005;27:781-96.

7. Bittner AC jr, Echeverria D, Woods JS, Aposhian HV, Naleway $\mathrm{C}$, Martin MD, et al. Behavioral effects of low-level exposure to $\mathrm{Hg} 0$ among dental professionals: a cross-study evaluation of psychomotor effects. Neurotoxicol Teratol. 1998;20:429-39.

8. Lenvik K, Woldbæk T, Halgard K. Kvikksølveksponering blant tannhelsepersonell: en presentasjon av historiske måledata [Exposure to mercury among dental personnel: a presentation of historic measurement data; English summary]. Nors Tannlegeforenings Tid. 2006;116:350-6.

9. Norseth J. Kvikksølveksposisjon på offentlige tannklinikker i Oslo, en yrkeshygienisk vurdering [Mercury exposure in 
public dental offices in Norway; English summary] Nors Tannlegeforenings Tid. 1977;87:371-6.

10. Jokstad A. Mercury excretion and occupational exposure of dental personnel. Community Dent Oral Epidemiol. 1990;18:143-8.

11. Nilsson B, Nilsson B. Mercury in dental practice, I: the working environment of dental personnel and their exposure to mercury vapor. Swed Dent J. 1986;10:1-14.

12. Berlin M, Zalups RK, Fowler BA. Mercury. In: Nordberg GF, Fowler BA, Nordberg M, Friberg LT, editors. Handbook on the toxicology of metals. Amsterdam: Elsevier; 2007.

13. Heyer NJ, Echeverria D, Bittner AC jr, Farin FM, Garabedian CC, Woods JS. Chronic low-level mercury exposure, BDNF polymorphism, and associations with self-reported symptoms and mood. Toxicol Sci. 2004;81:354-63.

14. Ritchie KA, Gilmour WH, Macdonald EB, Burke FJ, Mc Gowan DA, Dale IM, et al. Health and neuropsychological functioning of dentists exposed to mercury. Occup Environ Med. 2002;59:287-93.

15. Hilt B, Svendsen K, Syversen T, Aas O, Qvenild T, Sletvold H, Melø I. Occurrence of cognitive symptoms in dental assistants with previous occupational exposure to metallic mercury. Neurotoxicology. 2009 May 7 [Epub ahead of print].

16. Hyson JM. Amalgam: its history and perils. J Calif Dent Assoc. 2006;34:215-29.

17. Joselow MM, Goldwater LJ, Alvares A Herndon J. Absorption and excretion of mercury in man, XV: occupational exposure among dentists. Arch Environ Health. 1968;17;39-44.

18. Gronka PA, Bobkoskie RL, Tomchick GJ, Bach F, Rakow AB. Mercury vapor exposure in dental offices. J Am Dental Assoc. 1970;81(4):923-25.

19. Baelum J, Pöckel H. Reference document on exposure to metallic mercury and the development of symptoms with emphasis on neurological and neuropsycological diseases or complaints. Department of Occupational and Environmental Medicine, Odense University Hospital, Odense (Denmark); 2007.

20. Buchwald H. Exposure of dental workers to mercury. Am Ind Hyg Assoc J. 1972;33:492-502.

21. Langworth S, Sällsten G, Barregård L, Cynkier I, Lind ML, Söderman E. Exposure to mercury vapor and impact on health in the dental profession in Sweden. J Dent Res. 1997;76:1397-404.
22. Ritchie KA, Burke FJT, Gilmour WH, Macdonald EB, Dale IM, Hamilton RM, et al. Mercury vapour levels in dental practices and body mercury levels of dentists and controls. $\mathrm{Br}$ Dent J. 2004;197:625-32.

23. Barregård L. Biological monitoring of exposure to mercury vapor. Scand J Work Environ Health. 1993;19 suppl 1:45-9.

24. Gundersen N, Lie A. Kvikksølveksponering ved tannlegekontorer: en epidemiologisk tverrsnittundersøkelse. [Mercury exposure in dental personnel: a cross-sectional epidemiological survey; English summary]. Yrkeshygienisk Institutt; Oslo (Norway); 1980. HD 834/800815.

25. Martin MD, Naleway C, Chou H-N. Factors contributing to mercury exposure in dentists. J Am Dent Assoc. 1995;126:1502-11.

26. Lönnroth E-C, Shahnavaz H. Amalgam in dentistry: a survey of methods used at dental clinics in Norrbotten to decrease exposure to mercury vapour. Swed Dent J. 1995;19:55-64.

27. Jones L, Bunnell J, Stillman J. A 30-year follow-up of residual effects on New Zealand Scool Dental Nurses, from occupational mercury exposure. Hum Exp Toxicol. 2007;26:367-74.

28. Bengtsson U. On the instability of amalgam [Internet]. In: Walhjalt B, editor. On reality. Bo Walhjalt and authors; 1997 [cited 9 February 2009]. Available from: http./www.gbg.bonet. se/bwf/art/instab/types.html

29. Wasserman O, Weitz M, Alsen-Hinrichs C. Kieler AmalgamGutachten 1997 [Amalgam statement 1997]. 2nd ed. Kiel (Germany): Institut für toxicologie im klinicum, ChristianAbrechts-universität; 1997.

30. Gjerde NR, Moen B. Kjemisk arbeidsmiljø: vurderinger basert på en spørreundersøkelse blant tannhelsesekretærer [A survey of dental nurses' assessment of the chemical working environment; English summary]. Nors Tannlegeforenings Tid. 2007;117:84-8.

31. Ahlborg GA. Validity of exposure data obtained by questionnaire: two examples from occupational reproductive studies. Scand J Work Environ Health. 1990;16:284-8.

32. Tielemans E, Heederik D, Burdorf A, Vermeulen R, Veulemans $\mathrm{H}$, Kromhout $\mathrm{H}$, et al. Assessment of occupational exposures in a general population: comparison of different methods. Occup Environ Med. 1999;56:145-51.

Received for publication: 13 May 2009 